\title{
FOREST FIRES IN NORTHERN CANADA
}

\author{
Robert Bell \\ Assistant Director, Geological Survey, Ottawa, Canada
}

Northward of the deciduous and mixed forests of Southern Canada a vast belt of conifers, about seven hundred miles in breadth, stretches for four thousand miles from the eastern coast of Labrador to the Rocky Mountains, and continues beyond them into Alaska. The northern zone of this belt consists of black and white spruce and tamarac, but as we go south these become mixed with Banksian pine, balsam fir, and in verge of the forest, there is also a greater or less mixture of aspen, roughbarked poplar, white birch, and the various northern willows, but in a general way this great belt may be described as a coniferous forest.

Notwithstanding its immense extent, it may be said that fire has run through every part of it at one period or another. Forests of this kind are particularly liable to destruction by fire.

The trees are comparatively small, and when they do not stand closely together their branches grow all the way to the ground. The open spaces, no matter how rocky, are covered with reindeer mosses, which, in the summer time, are as dry and flammable as tinder, while the deep carpeting of the yellow mosses among the trees themselves is equally dry and helps to give body to the flames.

The Indian hunter or wild Indian of the North, knowing how destructive forest fires are to the animals on which he depends for food and fur, takes all possible care to prevent them, yet if one ascends a high hill in any part of these regions so as to obtain an extensive view of the country he will find the normal condition of the woods to be "patchy," or to consist of areas of second growths of various ages mixed with others of old timber. The latter may have attained to the full growth and yet not represent the original forest, as it has probably sprung up on ground which had been burnt over at a time more remote than would represent the life of any of the trees standing upon it. The writer has crossed the entire breadth of our northern forests in many parts and has found the above condition to prevail everywhere.

Knowing the care which the Indians have always exercised, and the fact that the country has not been invaded by white men, the question arises, What caused these fires which have in turn swept over every part of this enormous country, and not only once, but again and again, since a very early period? My answer is that the conditions which we find in our Northern woods could not otherwise have been attained. These fires have had an effect on the formation of the soil, on the rotation of crops of trees, so necessary to their healthy condition, and on the dispersion of seeds.

We have both direct proof, and also the evidence of the trees themselves, that forest fires have originated without human agency, and that they have been going on ever since the present species of trees existed, if, indeed, they have not played a part in providing some of their specific characters. Lightning has been the commonest cause of these fires, although in some cases they may have originated from the spontaneous combustion due to the decomposition of pyrites, which is known to have set fire to beds of lignite in the Saskatchewan region.

In the Northern States and the inhabited parts of Canada it is not uncommon for lightning to strike barns and houses and to set them on fire in the hot months of summer. This is the season when our Northern forests are dry and ready to burn, and we should naturally ex- 
pect similar accidents to occur among them with the least equal frequency, in proportion to area. Examples have been observed in this region where the fire which has destroyed a large area has been traced back to a tree which had been struck by lightning. With an experience of over thirty summers spent in these woods, I only once actually witnessed a case of this kind. The lightning on this occasion was plainly seen to strike the brink of a wooded bluff near Red Rock, on Lake Superior, and set it on fire. Owing to the very small number of human beings in these regions, the chances of these occurrences being witnessed are very few as compared to civilized regions; yet the Indians tell me that they frequently happen. On several occasions I have found forest fires (still of limited extent) burning in totally uninhabited regions and where it was certain that no travellers could have passed for a long time before the fires begun. Among examples of this phenomenon which could be named were two observed on branches of the Attawapishkat, to the north of it, and one on the Sturgeon river, near Lake Nipissing.

Referring to the evidence afforded by the trees themselves that fires are natural phenomena, I shall mention the case of the Banksian pine. The cones of this tree are hard and remain closed as long as the tree lives. The older ones become weathered and covered with lichens, often indicating great age, still adhering firmly to the branch. The tree may fall down and rot and the cones drop from the decayed branches, yet they will not open. But should the tree become scorched by a forest fire, they will immediately gape open and healthy seeds will become scattered far and wide by the wind.

It sometimes happens that a second fire follows a previous one after a lapse of a few years. The first conflagration kills trees and consumes all the foliage and twigs, but leaves the charred trunks and branches standing. It also burns off the moss and much of the loamy soil. In time the branches fall off, the smaller roots become rotten, and a gale of wind some day levels all the trunks to the ground. This is called a "fire fall," and the prostrate trees cover the ground so completely that it is very difficult for the explorer to force his way under or over them. The second growth may have sprung up before it happened or it may begin to push its way through the tangled mass of fallen trees, rendering it almost impenetrable. Should another fire not occur, the second growth, consisting of deciduous trees, will attain its full size, and the fallen conifers gradually rot and disappear. But should a second fire appear during some dry summer, everything is swept away, including the upturned dried roots, which burn even more fiercely than the trunks and branches. The young second growth is entirely destroyed, and even the loamy part of the soil which may have escaped the first fire, including all seeds which may not yet have germinated. Only the scanty inorganic portion remains, heavily charged with the ashes of the wood and the loam. It is on ground thus prepared that groves of Banksian pine spring up and flourish. The seeds must have been scattered upon it after the second fire, which had so completely destroyed everything organic. The ground thus left remains almost bare for a few years, but at last it becomes pretty well occupied by the young pines of different ages as if the sowing process were a gradual one. A few spruces and other trees spring up. The reason Banksian pines are the first to occupy these lifeless areas may be due to the comparative lightness of their seeds and their extent of wing, enabling them to be carried greater distance in the wind or to their finding the excess of potash congenial to their development. They grow quickly, and in twenty years have attained a height of thirty feet and upwards, while some of their trunks are as thick as a man's thigh. By this time their branches bear a good crop of fresh-looking cones. I have never noticed a case where the seeds of this species germinated within the buried cone, as often happens with the spruce, 
balsam, \&c., resulting in tufts of young seedlings, and in all my observations go to show that fire is a necessary condition for the diffusion and maintenance of this tree in the manner above described. The same agency no doubt aids in scattering the seeds of other conifers. It is a well known fact that after a fire has destroyed a coniferous forest the growth which succeeds usually consists principally of deciduous trees. In the country under consideration these are aspen and rough-barked poplars, white birch, pigeon cherry, and willows.

After the vegetable loam has been burnt out by a forest fire, a long time must elapse before the soil regains an equal degree of fertility through the falling of leaves and the decay of generations of the small trees which follow, supposing that no new fire occurs to destroy again the accumulated mold and throw everything back to the sterile condition following the original double fire. In the end an increased fertility is probably reached, as the fires and the turning up of the root-bases of the trees all tend to disintegrate the rocky surface.

The length of time which has elapsed since a forest fire cannot be accurately ascertained, even if we could determine correctly the age of the second growth timber, as the new crop does not always start up immediately after the fire. In cases where the dates of such fires are known they are found to be several years further back than would be supposed if we if we judged solely by the new timber. The following is the course of events after a fire has run through a tract of the full-grown northern coniferous forest, the fires always occurring during the driest part of the summer: In the next spring weeds and bushes (raspberry, huckleberry, red alder, \&c.) begin to spring up and partly occupy the blackened ground. These increase for two or three years, and as they die out are gradually replaced by the poplars, white birch, pigeon cherry, willows, \&c., and a few conifers. The willows and pigeon cherry are short lived. The poplars attain their full size and decay in about seventy years, and the white birch shows signs of old age in less than one hundred years. In the meantime the proportion of conifers is constantly increasing from new individuals springing up, so that by the time the deciduous trees have died out the ground has become completely occupied by the former. The shade afforded by the latter causes the trunks of the spruces, tamaracs, \&c., to grow tall and straight. It may be remarked that in the northern regions referred to the tamarac grows everywhere on the dry ground, along with the spruces, poplars, \&c.

From the very extensive personal knowledge of the conditions of the forests of Northern Canada, I am able to state that fires have become more and more frequent as we approach the present time. The areas of the "brulés" of different dates may be said to be greater in proportion to their recentness. Various causes may be assigned for this increasing frequency of forest fires. The starting of fires by Indians of more than a hundred years ago, or before the introduction of modern methods, must have been a somewhat difficult matter. They probably obtained sparks by striking together pieces of iron pyrites as the Eskimos do at the present day, or ignited dry pounded wood fibre by means of wooded friction machines worked by bow and string; and occasionally they may have availed themselves of fires originated by lightning.

The most primitive Indian families I have met with paid great attention to keeping alive the fire they possessed, and carried it on their travels in old kettles, fed at frequent intervals by little dry sticks. The means of obtaining fire have been rendered much easier by the introduction of steel to be used with flint and punk, and of gunpowder by which to ignite rags, \&c., in their flint-lock guns, but above all by lucifer matches. The Indian, or for that matter the white man, who is fortunate enough to possess a stock of matches, when in the woods, very often avails himself of this easy means to make a smudge to keep off the mosquitoes, to light his pipe, dropping the burning 
match, or to make a little fire in order to boil his kettle and refresh himself with a hot drink. The number of fire-setting travellers has greatly increased in comparatively recent times. These include fur traders, missionaries, surveyors, explorers, prospectors, \&c. and, nearer to civilization, railway builders, common-road makers, lumbermen, bush-rangers, and sellers.

A fire may be set at a time of the year when it will not run, but it is astonishing how long it will smolder in the deep moss and under logs and roots, until after weeks, or even months, a dry time comes and a favoring gale of wind will fan it into activity and cause it to burn up the whole country side. The heaviest rains and the snows of the whole winter sometimes fail to extinguish or smother these smoldering fires.

In the course of my travels, during the last twenty summers, in the country between the great lakes and the St Lawrence and James' Bay, and between the Winnipeg basin and Hudson's Bay, forest fires were raging in some part of the area traversed each year, and indeed they may be said to be almost chronic. In all directions tracts of greater or less extent are burnt each year. We would frequently travel for long distances on rivers and chains of lakes along whose banks and on the hills and level lands beyond them, as far as the eye could reach, nothing could be seen but the naked and blackened trees left by the fires of the same or previous season; or it might be the equally dreary gray or bleached and shining trunks remaining from the fires from the previous years, and from which all the bark had dropped off. Even many miles away from one of these fires the smoke would be so dense as to completely hide the shore and islands of the lakes we were passing through, so that we were obliged, as it were, to feel our way along. On these occasions it became impossible to carry on surveying operations, which to be either abandoned or left for a future opportunity. The sun in the cloudless sky above would appear only as a dull red ball; burnt leaves and thin films of ashes would settle slowly to the earth like large flakes of snow, and the thick smoky air, after a time, became unpleasant for respiration and depressing to the spirits. This state of things might continue for days, but in the course of a few hours, a change in wind, especially if followed by rain, might clear the atmosphere and we would be able, for the first time, to view the country into which we had penetrated blindfolded

Should one of those fires occur early enough in the summer, the newly killed trees are quickly attacked by the boring beetles, but if late in the season, the borers operations are mostly postponed till the next year. These insects, finding such constant and almost unlimited feeding grounds, swarm to the "brulés" of the great coniferous forests of the North, and here, in a still evening, the creaking noise of the millions of their larvae may be heard for considerable distances in all directions.

Taking the whole of the great region just referred to, it is probably not too high an estimate to place the recently burnt portions at one-third of the entire areas and the portions covered by small second growths at another third, leaving only one-third as original forest and large second growth. When we consider the highly inflammable nature of these forests in summer and the constant danger to which they are exposed, it is a wonder that even this proportion has escaped the flames. It would be interesting and useful to show on a map the recently burnt areas and those occupied by the second growth of different ages, each to include, say, those of every twenty years, and I think I have the necessary data to enable me to do a large part of this work with sufficient accuracy for practical purposes.

The modern Indians, even in these northern wildernesses, have become every year more and more dependent upon the white man, and they rely less upon the resources of the country for the means of making a constant living than did their forefathers, who appear to have been a more thoughtful and independent 
class of men. In the course of the extensive travels in the North above referred to, I have taken every opportunity as a Government officer to warn the natives to be more careful about allowing the woods to catch fire, and on revisiting certain districts, after a few years, I have found that my advice had been followed, and that forest fires had not been nearly so common as previously. One of the reasons for the growing frequency of forest fires is that the Indians travel more than they did formerly (and thus make more fires than when they were accustomed to stay longer in one place), along with the fact that they are less careful to extinguish them when they are not on or near their own hunting grounds. It gives them some trouble to put out a fire completely when they leave a camp, or where they may have stopped to cook a meal or gum their canoe by the way, and an Indian will seldom do anything except by necessity. In the course of my own journeys I often hire Indians to travel with me only for limited distances, sending them back when I find fresh ones to take their places. In this way a considerable number generally come under my influence in the course of a season. I always make great pains to make these men extinguish all our fires, and instruct them to keep up the practice, even in their own interest, after they leave me. The fires for cooking breakfast or dinner are only allowed to be kindled on bare rocks or on the beach, where there is little danger of them spreading, and those which we are obliged to make in the woods for our camp at night are always carefully dug out and drenched with water and the moss all around saturated before leaving. On account of the fire burrowing under the dry moss, it is seldom completely extinguished by merely throwing a few kettlesful of water upon the brands. It requires to be dug out with sharp sticks, otherwise it will go on smoldering until a favorable opportunity allows it to burst into flames. As an additional precaution, I camp as often as possible upon small islands. In spite of all this care my party was once the unwit- ting cause of burning the woods on an island in the Nelson river. We had made our mid-day fire on a wide surface of sloping rock near the edge of the river and a considerable distance from the woods, and afterwards threw the brands into the water, as usual, and dashed some kettlesful all over the place where the fire had been. But on our return, two or three weeks afterwards, we found that a spark must have fallen unnoticed into the dry moss and loam of a long narrow crack in the rock, which ran up the edge of the woods, for we saw that the fire had followed this, like a train of gunpowder, and on reaching the bush the wind had fanned it into flame. Rotten coniferous wood, when thoroughly dry and broken up, or pulverized, is particularly tenacious of fire and it appears to seize eagerly on every spark that falls amongst it. It requires to be thoroughly blended with water before one can be certain that even some floating piece may not be alight in its centre.

Let us try to picture the conditions under which the great forest fires of Northern Canada take place. A whole country-side, of practically unlimited extent, is densely clothed with conifers, mostly spruces, balsam, tamarac, and Banksian pine. The trees are crowded so closely together that their branches touch or intermingle. The ground is deeply covered with dry grass. After prolonged hot weather and drouth the moisture becomes thoroughly dried out of the gummy leaves and branches, leaving the resin and turpentine ready for ignition. All the conditions are now present, and only await a spark of fire to give rise to one of the wildest scenes of destruction of which the world is capable. When the fire has once started, the pitchy trees burn rapidly; the flames rush through their tops and high above them with a roaring noise. Should the atmosphere be calm, the ascending heat soon causes the air to flow in, and after a time the wind acquires great velocity. An irresistible front of flame is soon developed, and it sweeps forward, devouring the forest before it like the dry grass in 
a running prairie fire, which this resembles, but on a gigantic scale. The irregular line of fire has a height of a hundred feet or more above the trees, or two hundred feet from the ground. Great sheets of flame appear to disconnect themselves from the fiery torrent and leap upward and explode, or dart forward, bridging over open spaces, such as lakes and rivers, and starting the fire afresh in advance of the main column, as if impatient of the slower progress which it is making. These immense shooting flames are probably due to the large quantities of inflammable gas evolved from the heated tree tops just in advance of actual combustion, and they help to account for the almost incredible speed of some of the larger forest fires, one of which was known to run about 130 miles in twelve hours, or upwards of ten miles per hour.

The wild animals appear to understand the significance of the roaring noise and the clouds of smoke in the sky in advance of these conflagrations and far ahead of the actual flames; the terrified deer, bears, wolves, and lynxes may be seen fleeing for their lives, followed by multitudes of the small fur-bearing animals, hares, \&c., all of which are, however, soon overtaken and destroyed. Should the larger creatures be so fortunate as to reach a lake or river in time, they may escape along with the beavers, muskrats, and otters, which seldom stray far from water; but it not infrequently happens that bears and other animals, which have been roasted in these fires, are found and eaten by the Indians after they have passed over. The birds flutter up in confusion in advance of the wall of fire and appear to drop back into the flames. Human beings sometimes perish in these catastrophes, as happened to a number during the surveys for the Canadian Pacific Railway.

Should the smoke be carried by the wind in such a direction that one of these fires may be witnessed at night, the scene is one of the grandest which it is possible to imagine, and may be compared to the burning of a great city with a line of fire extending far out of sight. The feeling of distant solitude, combined with the view of such wide-spread destruction, gives the mind an impression of weird grandeur which can scarcely be conceived under any other circumstances.

In the more southern districts of Canada, where the timber consists largely of white and red pine, the character of the forest fires is somewhat different, being less rapid and not so complete in its effects. This is owing to the more open nature of both the timber and its foliage, the trees growing further apart and having almost naked trunks, and also to the circumstance that they are generally mixed with deciduous trees, all of which prevent the fire from acquiring such a strong body as in the coniferous thickets of the north. Still, fires are sometimes moderately extensive in the pine woods and destroy large quantities of those more valuable timber trees.

I do not propose to go into the question of how far, if at all, these great forest fires affect the rain-fall in the northern districts. Only accurate observations on the ground and extending over a long period of years could determine the matter satisfactorily. It is worthy of remark, however, that around most of the lakes ancient water-marks may be seen on the rocks high above any which have been reached for a great length of time, as proved by the growth of lichens. But it is possible that this may be due to permanent lowerings of these lakes by the gradual deepening of their outlets.

Let me now proceed to make some kind of calculation of the quantity of available fuel which is destroyed in a given area by a northern forest fire, apart from any further value which the coniferous trees of the north may have as timber for local purposes or for export. An acre of the original forest, of the character already described, or of the full-size second growth, would produce on an average twenty to thirty cords of good wood in addition to the branches and roots, as compared to fifty or sixty cords which might be attained from an acre 
of heavy hard-wood bush. Taking into account both the older and younger second growths of these regions the average might not produce more than at the rate of ten to fifteen cords per acre. Still, at the low estimate of fifteen cords for the average of the old timber and second growths, each square mile (640 acres) would yield 9,600 cords. If we now take a comparative small portion of our vast northern coniferous forest, say an area the size of Great Britain, or 89,000 square miles, it may safely be said to bear $854,400,000$ cords of good wood. The population of all Canada from the Atlantic to the Pacific is about five millions, the greater number of whom live in the milder parts; but supposing that an average of twenty cords of this fuel, per family, would be required for a year's consumption and that there are one million families, we have here sufficient fuel for all domestic purposes for a period of upward forty-two years, or till a new crop, affording an equal quantity could be grown; so that if properly protected from fire, this limited area is capable of supplying a population of five million people with abundance of fuel to warm their houses and cook their food for all time. A much smaller area must necessarily have served all the wants of the more numerous British people themselves, both for fuel and other purposes, before they discovered the use of mineral coal, as a large proportion of the island was either cultivated, or under forests which were never cut down for fuel; and again, open or rocky country, like much of Scotland and Wales, must be taken into account. Our northern forest-belt is more than thirty times as extensive as Great Britain, and it is probable that, at the rate of destruction which has been going on in recent years, more than a thirtieth part of it, or an equal area to England, Scotland, and Wales, is burnt off annually; or, in other words, we are losing every year as much fuel as would supply the domestic wants of the whole Dominion for nearly half a century.

Can anything be done to prevent or lessen this terrible waste? One would naturally sup- pose that this question would be looked upon as of the first importance by the people of Canada, as a similar one is regarded in Scandinavia, more especially when we consider that almost the whole of this enormous area is destitute of coal or lignite, and that its greatest industry, if it is ever to be populated at all, will be the mining and reduction of metals, in both of which operations much wood is required, besides what may be wanted for domestic and other purposes. Yet our people never appear to give the matter much thought, and indeed the subject is seldom even mentioned. Laws against the willful or negligent starting of fires in the woods have been placed on the statutebooks of the organized provinces, in which some kinds of timber have a present commercial value, but these ordinances have practically little effect, as no adequate provision is made for their enforcement. Besides the laws themselves, we require the necessary machinery to carry them out. What is wanted is a proper number of paid officers or forest guardians, each with a staff of men, whose duty it would be to look after the timber districts, whether belonging to the Crown or leased as limits to the lumbermen. These officers and their men should have power to arrest or lay information against persons suspected or known to have willfully or by their negligence set fire to the woods. As matters now stand, many guilty persons are allowed to escape through the reluctance or fear which disinterested or private individuals may have in regard to informing against them. It is not to be expected that a private citizen will voluntarily assume the odium, trouble, expense, and loss of time necessary to do what is as much the duty of every member of the community for the general good of the country. The work would not be so unpleasant in the hands of a paid government officer clothed with ample authority. Lumbermen are often blackmailed by bad characters whom they have been obliged to dismiss from their service and whose movements they cannot watch, but who 
they know would be very apt to set fire to their limits for the sake of revenge. The forest guardians should keep an eye not only on such persons, but even on careless Indians, explorers, and bush-travellers generally. These officers, and also the head men of all the lumbering establishments in the woods, should be empowered to call out every man within reach to fight forest fires when they break out. Our fish and games laws are also, to a great extent, a dead letter from a similar want of executive force, and it would probably be found advantageous also to utilize the services of the forest guardians in assisting to carry them into effect.

In Scandinavia, where preservation of the forests is regarded as of vital importance, the laws against setting them on fire are very severe. Any person who may have caused a forest fire, whether by "accident" or otherwise (no accidents being recognized in connection with this matter), is held liable for all he is worth toward making good the damage, and he is imprisoned besides. Under these circumstances forest fires are very rare. The climate of Scandinavia in summer is more damp than ours, and lightning is less frequent, so that strict forest regulations are more urgently required with us. Laws of much less severity than those referred to, if they could be uniformly enforced in Canada, would soon have an appreciable effect in preventing the wholesale destruction of valuable standing timber which is going on to such an alarming extent in this country.

Reprinted from the Proceedings of the American Forestry Congress, December 1888, Gibson Brothers Printers and Bookbinders, Washington, D.C. The journal appreciated the availability of the contents of this article through Google Book Search. 